$\underline{\text { Review }}$

\title{
Outcome of Allogeneic Stem Cell Transplantation Following Reduced-Intensity Conditioninig Regimen in Patients With Idiopathic Myelofibrosis: the G.I.T.M.O. Experience
}

Francesca Patriarca ${ }^{1}$, Andrea Bacigalupo ${ }^{2}$, Alessandra Sperotto ${ }^{1}$, Miriam Isola ${ }^{3}$, Barbara Bruno ${ }^{2}$, Maria Teresa van Lint ${ }^{2}$, Anna Paola Iori ${ }^{4}$, Paolo Di Bartolomeo ${ }^{5}$, Maurizio Musso ${ }^{6}$, Pietro Pioltelli ${ }^{7}$, Giuseppe Visani $^{8}$, Pasquale Iacopino ${ }^{9}$, Renato Fanin ${ }^{1}$ and Alberto Bosi ${ }^{10}$.

${ }^{1}$ Division of Hematology and Cellular Therapies Unit 'Carlo Melzi', Dpt. of Morphological and Clinical Researches, University of Udine, ${ }^{2}$ II Hematology Division, San Martino Hospital, Genova, ${ }^{3}$ Statistics Institute, Dpt. of Morphological and Clinical Researches, University of Udine, ${ }^{4}$ Hematology Division, 'La Sapienza' University, Roma, ${ }^{5}$ Hematology Department, Pescara Hospital, ${ }^{6}$ Oncohematology Unit, 'La Maddalena' Hospital, Palermo, ' Internal Medicine and Hematology Division, 'S. Gerardo de' Tintori' Hospital, Monza, ${ }^{8}$ Division of Hematology, Pesaro Hospital, ${ }^{9}$ Division of Hematology, Reggio Calabria Hospital, ${ }^{10}$ Hematology Division, Azienda Ospedaliera Careggi, University of Firenze.

Competing interests: The authors have declared that no competing interests exist.

Published: May 8, 2010

Received: April 24, 2010

Accepted: May 3, 2010

Mediterr J Hematol Infect Dis 2010, 2(1): e2010010, DOI 10.4084/MJHID.2010.010

This article is available from: http://www.mjhid.org/article/view/5907

This is an Open Access article distributed under the terms of the Creative Commons Attribution License (http://creativecommons.org/licenses/by/2.0), which permits unrestricted use, distribution, and reproduction in any medium, provided the original work is properly cited.

\begin{abstract}
Background: Allogeneic stem cell transplantation (SCT) is a potentially curative treatment for myelofibrosis (MI), though limited by a high rate of transplant-related mortality (TRM). In the present study we evaluate the outcome of MI patients undergoing an allogenic SCT after reduced intensity conditioning (RIC) regimens, and the impact of prognostic factors.

Design and methods: Fifty two patients were transplanted in 26 Italian centres between 1998 and 2006. We analyzed the influence of patient and disease clinical features before SCT and of transplant procedures on TRM and overall survival (OS) by means of univariate and multivariate analyses.

Results: At SCT, median age was 52,5 years $(32-68)$ and $89 \%$ of the patients had an intermediate or high Dupriez score. Conditioning regimens were based on fludarabine plus busulphan in $27 \%$ of patients, thiotepa plus cyclophosphamide in $46 \%$ and miscellaneous drug combinations in the other $27 \%$ of cases. Stem cells came from matched sibling donors for $75 \%$ of the patients and mismatched sibling or unrelated donors for the remaining $25 \%$. The cumulative incidence of engraftment at day 90 after transplant was $83 \%$ (95\% CI, 0.87 0.97). The estimated 1-year TRM was $30 \%$. The estimated 3-year event-free-survival (EFS) and OS after hematopoietic SCT was $44 \%$ and $38 \%$ respectively. In multivariate analysis, an higher leukocyte count and circulating blasts in the peripheral blood before SCT significantly reduced EFS and OS respectively.
\end{abstract}


Interpretation and conclusions: We conclude that the extension of the disease before transplantation based on the presence of circulating blasts and high leukocyte counts significantly affected the outcome after HSCT

Introduction: Myelofibrosis (MI) is a clonal hematopoietic stem cell disorder that is clinically characterized by progressive anemia, marked splenomegaly, extramedullary hematopoiesis, constitutional symptoms and a significant risk of evolution into acute leukaemia. MI can appear as a primitive or idiopathic disorder or, less frequently, as a secondary complication of essential thrombocythemia or polycythemia vera, with a clinical presentation and course similar to the idiopathic form. The disease affects mainly elderly people, with a median age at diagnosis of about 65 years. It is a heterogeneous disorder in term of presentation and evolution, with a median overall survival (OS) varying between 2 and 15 years, depending on the presence or absence of clinically defined prognostic factors. Adverse prognostic factors for survival have included advanced age, marked anemia, leukocytosis or leukopenia, abnormal karyotype, constitutional symptoms and presence of circulating blasts Moreover, the prognostic value of cytogenetic abnormalities, increased number of circulating CD34+ cells in peripheral blood and JAK2 mutational status has been also evaluated. The available prognostic score systems are mainly based on clinical variables. The most widely used is the Dupriez score $^{1}$, which is based on hemoglobin level and leukocyte count. The Mayo Clinic Group tried to improve the Lille score by adding thrombocytopenia and monocytosis. ${ }^{2}$ The International Working Group for Myelofibrosis Research and Treatment (IWGMRT) recently proposed a new scoring system analyzing the largest patient population and recognized 5 main unfavourable variables which were: age $>65$ years, presence of constitutional symptoms, and circulating blasts cells $\geq 1 \%$, anemia and leucocytosis. ${ }^{3}$ All these prognostic systems could clearly separate intermediate or high risk patients (with a median survival ranging between 1 and 4 years) from patients with a favourable prognosis (median survival of 8-10 years).

Drug therapy is aimed at alleviating the symptoms, and has not been shown to improve survival. Allogeneic hematopoietic stem cell transplantation (HSCT) is the only treatment with the potential for curing $\mathrm{MI}$ and has been performed in patients with unfavourable clinical variables for several years. The application of HSCT in MI is strongly limited by an unacceptable rate of transplantation-related toxicity occurring in patients receiving standard myeloablative conditioninig. In fact, transplant-related mortality (TRM) ranged from 25 to $48 \%$ in different studies. ${ }^{4-9}$ The discovery that allogeneic stem cell can engraft patients prepared with nonmyeloablative doses of radiochemotherapy has led to the rapid development of a variety of reduced-intensity conditioning (RIC) regimens that have been successfully applied to patients with MI who would not be candidate for standard myeloablative HSCT due to advanced age or co-morbidities. RIC regimens might theoretically be applied to a large number of patients with an older age and comorbidities, while maintaining the potential for eradicating the disease based on the graft-versus MI effect. ${ }^{10-14}$ Studies in small series of patients who underwent RIC HSCT demonstrated the feasibility of the procedure, and reported encouraging TRM rates below $15 \%$ and OS rates around $80 \%$. However, the patients included were a few and the follow-up was still short. RIC regimens were heterogeneous and included fludarabine plus low dose TBI or alkylating agent (busulfan or melphalan).

We have already published the analysis of the data of the Gruppo Italiano Trapianto Midollo Osseo (G.I.T.M.O.) Registry regarding a total of 100 patients with MI, who underwent allogeneic HSCT in 26 different Italian Transplant Centres between 1986 and 2005. ${ }^{15}$ Herein we present a subanalysis limited to the patients who had received RIC regimens in more recent years, with the aim of analysing clinical features of patients and transplants and identifying prognostic factors affecting the outcome after HSCT.

Methods: Data were collected in an XLS database and imported into Stata/SE 9.0 for Windows for the statistical analysis. The end-points were engraftment, acute and chronic graft-versus-host disease (GVHD), relapse, TRM, overall survival (OS) and event-free survival (EFS).

TRM was defined as death due to all causes not related to MI. OS was defined as the time (months) from date of transplant to either death or last observation. EFS was defined as the time from date of transplant to relapse, death or last observation. OS and EFS were described using the 
Kaplan-Meier approach. Analysis of survival was done using Cox proportional hazard models, after the proportional hazards assumption had been verified. All variables considered in univariate analysis as possible prognostic factors were: primary diagnosis (primary or secondary MI), Dupriez score at transplant (low, intermediate, or high), transplant time (before and after 2001), interval between diagnosis and transplantation (months), transfusions before transplant, hemoglobin levels, leukocyte cell counts, circulating blasts, karyotype, previous splenectomy, splenomegaly at transplantation, age at transplantation, drugs of the conditioning regimen (fludarabine plus busulphan or thiotepa plus cyclophosphamide or other miscellaneous regimens), source of stem cells (marrow or peripheral blood), acute GVHD (grade 0-I or grade II-IV), and chronic GVHD (absent or limited or extensive). Multivariate stepwise analyses included all variables significant at $\mathrm{p} \leq 0.10$ in an univariate analysis. Retention in the stepwise model required the variable to be significant at $\mathrm{p} \leq 0.05$ in a multivariate analysis.

Results: A total of 52 patients were transplanted between January 1998 and December 2006. (table 1 and 2). Median time between diagnosis and HSCT was 13 months (1-161). At the time of HSCT, median age was 52,5 years (32-68), $89 \%$ of the patients had a Dupriez score $\geq 1,45 \%$ had previously received red cells transfusions, $27 \%$ had blasts in the peripheral blood, $22 \%$ had an abnormal karyotype, $51 \%$ had splenomegaly, $43 \%$ underwent splenectomy before HSCT. Conditioning regimens were based on fludarabine plus busulphan in $27 \%$ of patients, thiotepa plus cyclophosphamide in $46 \%$ and miscellaneous drug combinations in the other $27 \%$ of cases. Stem cells came from matched sibling donors for $75 \%$ of the patients and mismatched sibling or unrelated donors for the remaining $25 \%$. Thirty-five per cent received bone marrow and $65 \%$ peripheral blood stem cells. Median time of follow-up after HSCT was 13 months for the whole population and 34 months for surviving patients. Eighty-three per cent achieved full engrafment. Eighteen patients developed acute GVHD grades II to IV for a cumulative incidence of $38 \%$ by day 100 after transplantation $(95 \% \mathrm{CI}$ $0.9-1.3)$. Chronic GVHD occurred in 20 patients for a cumulative incidence of $50 \%$ at 2 years $(95 \%$ CI0.4-0.8): it was limited in 14 patients and extensive in 6 patients. One-year TRM was $30 \%$. The cumulative incidence of relapse was $19 \%$ at 1 year.
Table 1: Clinical and haematological characteristics of the patients at allergeneic stem cell transplantation.

\begin{tabular}{|c|c|}
\hline Total no. Patients & 52 \\
\hline \multicolumn{2}{|l|}{ Age } \\
\hline Median (range) & $52,5(32-68)$ \\
\hline \multicolumn{2}{|l|}{ Diagnosis } \\
\hline Idiopathic myelofibrosis & $36 / 44(82 \%)$ \\
\hline Secondary myelofibrosis & $8 / 44(18 \%)$ \\
\hline \multicolumn{2}{|l|}{ Time diagnosis-SCT ( months) } \\
\hline Median (range) & $13(1-162)$ \\
\hline$\leq 12$ & $21 / 52(40 \%)$ \\
\hline $13-35$ & $14 / 52(27 \%)$ \\
\hline$\geq 36$ & $17 / 52(33 \%)$ \\
\hline \multicolumn{2}{|l|}{ Dupriez score at transplant } \\
\hline Low & $5 / 44(11 \%)$ \\
\hline Intermediate & $30 / 44(68 \%)$ \\
\hline High & $9 / 44(21 \%)$ \\
\hline Previous transfusions & $18 / 40(45 \%)$ \\
\hline \multicolumn{2}{|l|}{ Karyotype } \\
\hline Normal & $28 / 36(78 \%)$ \\
\hline Abnormal & $8 / 36(22 \%)$ \\
\hline Previous splenectomy & $20 / 46(43 \%)$ \\
\hline Splenomegaly at transplant & $22 / 43(51 \%)$ \\
\hline Circulating blasts at transplant & $11 / 41(27 \%)$ \\
\hline \multicolumn{2}{|l|}{ Hemoglobin level at transplant $(\mathrm{g} / \mathrm{dl})$} \\
\hline Median (range) & $9.1(5.6-14.4)$ \\
\hline \multicolumn{2}{|l|}{ White cell count at transplant $\left(x 10^{6} / l\right)$} \\
\hline Median (range) & $7.7(0.6-118)$ \\
\hline
\end{tabular}

The estimated 3-year EFS and OS were respectively $44 \%$ and $38 \%$. In univariate analysis factors associated with an higher TRM rate were: an older transplant date $(1998-2000$ vs 2001-2006: $\left.\mathrm{HR}=0.25 ; \mathrm{CI}_{95 \%}[0.09 ; 0.68] ; \mathrm{p}=0.007\right)$ and presence of grade II-IV acute GVHD (HR 2.42; $\mathrm{CI}_{95 \%}[0.92-$ 6.38]; $\mathrm{p}=0.073$ ), The final survival model did not show any significant prognostic factor for TRM. Prognostic factors that were significantly 
Table 2: Transplant-related characteristics

\begin{tabular}{|l|c|}
\hline Year of the transplant & \\
\hline $1998-2000$ & $8 / 52(15 \%)$ \\
\hline $2001-2006$ & $44 / 52(85 \%)$ \\
\hline Donor & \\
\hline HLA matched sibling & $39 / 52(75 \%)$ \\
\hline Unrelated or HLA "mismatched" sibling & $13 / 52(25 \%)$ \\
\hline & \\
\hline Source & \\
\hline Bone marrow & $18 / 52(35 \%)$ \\
\hline Peripheral blood & $34 / 52(65 \%)$ \\
\hline & \\
\hline Conditioning regimen & \\
\hline Fludarabine plus busulphan & $14 / 52(27 \%)$ \\
\hline Thiotepa plus cyclophosphamide & $24 / 52(46 \%)$ \\
\hline Fludarabine- 2 Gy TBI & $4 / 52(8 \%)$ \\
\hline Fludarabine-melphalan & $6 / 52(11 \%)$ \\
\hline Other & $4 / 52(8 \%)$ \\
\hline
\end{tabular}

$(\mathrm{p} \leq 0.10)$ associated with EFS in the univariate proportional hazards model were: transplant time (1998-2000 vs 2001-2006: $\mathrm{HR}=0.46$; $\mathrm{CI}_{95 \%}[0.19 ; 1.15] ; \mathrm{p}=0.098$ ), leukocyte count before transplantation $\quad\left(\mathrm{HR}=1.00002 ; \quad \mathrm{CI}_{95 \%}\right.$ [1.000002:1.000032]; $\mathrm{p}=0.028)$ and presence of chronic extensive GVHD $\left(\mathrm{HR}=0.27 ; \quad \mathrm{CI}_{95 \%}\right.$ [0.06;1.26]; $\mathrm{p}=0.095)$. In multivariate analysis only an higher leukocyte count before HSCT was significantly associated with an unfavourable EFS $\left(\mathrm{HR}=1.000028 ; \quad \mathrm{CI}_{95 \%} \quad\right.$ [1.000011:1.000045]; $\mathrm{p}=0.001)$. In univariate analysis factors that affected OS were: presence of blasts in the peripheral blood before transplantation $\left(\mathrm{HR}=3.37 ; \mathrm{CI}_{95 \%}[0.36 ; 2.39]\right.$; $\mathrm{p}=0.020$ ), an higher leukocyte count before transplantation $\quad\left(\mathrm{HR}=1.00002 ; \quad \mathrm{CI}_{95 \%}\right.$ [1.000002:1.000035]; $\mathrm{p}=0.032$ ), an older transplant date $\left(1998-2000\right.$ vs 2001-2006: $\mathrm{HR}=0.32 ; \mathrm{CI}_{95 \%}$ [0.21;0.82]; $\mathrm{p}=0.018)$. In multivariate analysis circulating blasts in the peripheral blood before transplantation significantly reduced OS $\left(\mathrm{HR}=3.356 ; \mathrm{CI}_{95 \%}[1.21 ; 9.34] ; \mathrm{p}=0.020\right)$.

Discussion: We recently reported data on a population of 100 patients with MI who underwent allogeneic HSCT in 26 transplant centers that are part of the GITMO in a 20-year period between 1986 and 2006 and we retrospectively analyzed the influence of patient and disease clinical features before SCT and of transplant procedures on TRM and OS. ${ }^{15}$ We confirmed that MI remains a rare indication for SCT with the recruitment of about 15-17 cases per year since 2002 and observed a great heterogeneity in terms of conditioning regimens, GHVD prophylaxis and supportive measures. Although we observed a significative and progressive improvement of TRM after 1996, we could not recognized any significative difference in outcome either between patients treated with myeloablative versus RIC regimens or among those treated with different regimens. The lack of any association between intensity of conditioning or type of drugs included in the preparative regimen could be in part due to the great heterogeneity of transplant procedures. The present analysis is limited to the patients who had received RIC regimens, with the aim of identifying prognostic factors affecting the outcome after HSCT. This study confirms that outcome after RIC transplants has been progressively improved in the last decade. However, transplant toxicity is still a matter of concern, since we observed a 1- year TRM of $30 \%$ that is higher than that reported in previously published series after RIC transplants (4-6) and similar to TRM observed after myeloablative transplants. ${ }^{10-14}$ The extension of the disease before transplantation based on the presence of circulating blasts and high leukocyte counts significantly affected both EFS and OS after HSCT. These two parameters are both included in well-known prognostic scoring systems: the leukocyte count in the Dupriez score and the circulating blasts percentage in the IWGMRT one. These scoring systems, that were validated in non-transplanted patients, have demonstrated to impact the outcome after the transplant, too. In our series of patients we could not identify any transplant procedure (conditioning regimen or stem cell source or donor) influencing outcome, probably because of the small number of patients examined and the heterogeneity of chemotherapy and immunosuppressive drugs delivered. However, the most commonly used RIC regimen was the association of thiotepa and cyclophosphamide, that was administered to nearly half of the patients. Thiotepa is known to be a radiomimetic drug with a potent myeloablative activity associated with an immunosuppressive effect and minimal toxicity. The combination of thiotepa and cyclophosphamide was originally described for autologous transplants, ${ }^{16}$ then it was incorporated in the conventional preparative regimens for T-cell depleted allogeneic SCT from HLA matched and haploidentical sibling donors. ${ }^{17-18}$ The Genova group reported that thiotepa at the dose 
Table 3. Summary of the previously reported clinical results of allogeneic stem cell transplantation following reduced-intensityconditioning transplants in myelofibrosis.

\begin{tabular}{|c|c|c|c|c|c|c|}
\hline & Rondelli $^{10}$ & Synder $^{12}$ & Merup $^{14}$ & Kroger $^{23}$ & Bacigalupo $^{26}$ & $\begin{array}{c}\text { Present } \\
\text { GITMO series }\end{array}$ \\
\hline $\mathbf{N}^{\circ}$ pts & 21 & 9 & 10 & 103 & 46 & 52 \\
\hline Median age & $54(27-68)$ & $54(46-68)$ & $40(5-63)$ & $51(24-67)$ & $55(32-68)$ & $52(32-68)$ \\
\hline $\begin{array}{c}\text { RIC } \\
\text { Conditioning }\end{array}$ & $\begin{array}{c}\text { Fluda }+ \text { busulfan } \\
\text { Thiotepa+cy } \\
\text { Fluda }+ \\
\text { melphalan } \\
\text { Fluda + TBI } \\
\end{array}$ & $\begin{array}{c}\text { Fluda+ } \\
\text { Melphalan } \\
\text { Fluda + TBI }\end{array}$ & $\begin{array}{l}\text { Fluda+ busulfan } \\
\qquad \begin{array}{c}\text { Fluda+Cy+ } \\
\text { melphalan }\end{array}\end{array}$ & $\begin{array}{c}\text { Fluda }+ \\
\text { busulfan }\end{array}$ & $\begin{array}{c}\text { Thiotepa }+ \text { cy } \\
\pm \text { melphalan }\end{array}$ & $\begin{array}{c}\text { Fluda }+ \text { busulfan } \\
\text { Thiotepa }+ \text { cy }\end{array}$ \\
\hline $\begin{array}{c}\text { Donor } \\
\text { REL/UNREL }\end{array}$ & $19 / 2$ & $2 / 7$ & $20 / 7$ & $33 / 70$ & $32 / 14$ & $39 / 13$ \\
\hline $\begin{array}{l}\text { Median } \\
\text { follow-up } \\
\text { survivors } \\
\end{array}$ & 31 months & 32 months & 50 months & 33 months & 39 months & 34 months \\
\hline 1 y-TRM \% & $9 \%$ & $44 \%$ & $29 \%$ & $16 \%$ & $24 \%$ & $30 \%$ ( at $1 \mathrm{y}$ ) \\
\hline $3 y-\operatorname{OS} \%$ & $78 \%$ (at $2 \mathrm{y}$ ) & $56 \%$ & $70 \%$ & $67 \%$ (at $5 y$ ) & $45 \%$ (at $5 \mathrm{y}$ ) & $44 \%$ (at $3 \mathrm{y}$ ) \\
\hline 3 y -relase & $9 \%$ & $0 \%$ & Not evaluable & $22 \%$ & $19 \%$ & $19 \%$ \\
\hline
\end{tabular}

of $15 \mathrm{mg} / \mathrm{kg}$ and cyclophosphamide at the dose of $120-150 \mathrm{mg} / \mathrm{kg}$ produced complete engraftment and remission in 29 out of 31 patients, mostly with advanced disease. ${ }^{19}$ In a subsequent study, the same regimen with a $30 \%$ reduction of both drug doses was well tolerated by patients between 45 and 60 years with advanced leukemias, although half of the patients had persisting or relapsing disease. ${ }^{20}$ The incorporation of thiotepa in RIC regimens have represented an innovation in several Italian studies for different haematological diseases: thiotepa in association with cyclophosphamide and/or fludarabine followed by haematopoietic stem cells have demonstrated high feasibility and effectiveness in elderly patients with acute leukemias, ${ }^{20}$ in heavily pretreated relapsed or refractory lymphomas ${ }^{21}$ and in myelodisplastic syndromes. ${ }^{22}$

How do our study results compare with those already reported? Table 3 summarized the clinical results of the studies published. Most of them were retrospective and include small series of patients. The largest series was reported by Kroeger on behalf of the European Group for Blood and Marrow Transplantation. ${ }^{23}$ The study was prospective and included 104 patients mainly with intermediate or high risk score who received a conditioning regimen based on fludarabine 180 $\mathrm{mg} / \mathrm{mq}$ and busulfan $8 \mathrm{mg} / \mathrm{kg}$ i.v or $10 \mathrm{mg} / \mathrm{Kg}$ p.o and hematopoietic stem cells coming from sibling or unrelated donors. Engraftment was 99\%; 1-year TRM was $16 \%$ and was significantly increased in patients older than 50 years, in cases with intermediate and high-risk MI and after transplants from mismatched donors. Five-year OS was 67\% and 5 -year EFS was $51 \%$. Relapse rate was higher in splenectomized patients and if disease duration prior transplant was $>24$ months. Moreover, Kroeger reported that this conditioning regimen induced a JAK-2 negativity in $78 \%$ of patients carrying the V617-JAK2 mutation before transplant $^{24}$ and produced a rapid regression of bone marrow fibrosis in 59\% of patients al day +100 and in $100 \%$ of patients at day $+360 .{ }^{25}$ At present, the busulfan-fludarabine regimen could be considered as the RIC regimen that has been tested on the largest patient population and demonstrated the best results in terms of feasibility and clinical, molecular and histological responses.

The largest single center experience was reported by Bacigalupo et $\mathrm{al}^{26}{ }^{26}$ concerning 46 patients who had received a RIC regimen based on thiotepa and cyclophosphamide. TRM was $24 \%$ and 5 -year OS was $45 \%$ in the whole population, but it ranged from $8 \%$ to $77 \%$ according to the risk category. One of the most important contributions of these recent studies is the identification of the 
prognostic factors that influence the outcome after HSCT. Among the transplant-related variables, transplants from unrelated donors had a significative worse OS in comparison with sibling transplants in the Italian series ${ }^{15}$ and in the Genova study, ${ }^{26}$ while in the German study $^{23}$ only mismatched unrelated donors had an unfavourable impact on OS. Among the disease-related variables, Dupriez score identified significative differences in the outcome after SCT in the German study, ${ }^{23}$ while Bacigalupo $^{26}$ recognized large splenomegaly and higher than 20 red cell transfusions before transplant as powerful unfavourable predictors for OS. Role of splenectomy is still a controversial issue. Patients with large splenomegaly at transplant can have a slower granulocyte and platelet recovery, an higher risk of graft failure or persistence of splenomegaly for several months after transplant. ${ }^{27-}$

${ }^{28}$ However, splenectomy is associated of a $25 \%$ rate of bleeding and thrombotic complications and $6 \%$ perioperative deaths in patients with myelofibrosis. ${ }^{29}$ The increased risk of relapse after transplant in splenectomized patients observed in the German study was not confirmed in other series

\section{References:}

1. Dupriez B, Morel P, Demory JL et al. Prognostic factors in agnogenic myeloid metaplasia: a report on 195 cases with a new scoring system Blood 1996, 88: 1013-1018

2. Elliott MA, Verstovsek S, Dingli D, Schwager SM, Mesa RA, Li Cy, Tefferi A. Monocytosis is an adverse prognostic factor for survival in younger patients with primary myelofibrosis Leuk Res 2007; 31: 1503-1509

3. Cervantes F, Dupriez B, Pereira A, Passamonti F, Reilly JT, Morra E, Vannucchi AM, Mesa RA, Demory JL, Barosi G, Rumi E, Tefferi A. A new prognostic scoring system for primary myelofibrosis based on a study of the international Working Group for Myelofibrosys Research and Treatment . Blood 2009; 113: 2895-2901

4. Guardiola P, Anderson JE, Bandini G et al. Allogeneic stem cell transplantation for agnogenic myeloid metaplasia: a European Group for Blood and Marrow Transplantation, Sociètè Francaise de Greffe de Moelle, Gruppo Italiano per il Trapianto di Midollo Osseo and Fred Hutchinson Cancer Research Center Collaborative Study. Blood 1999, 93: 2831-2838

5. Deeg HJ, Gooley TA, Flowers ME et al. Allogeneic hematopietic stem cell transplantation for myelofibrosis. Blood 2003, 102:3912-3918.

6. Kerbauy DMB, Gooley TA, Sale GE et al Hematopoietic cell transplantation as curative therapy for idiopathic myelofibrosis, advanced polycythemia vera and essential trombocythemia. Biol Blood Marrow Transplant 2007, 13:355-365.

7. Guardiola P, Anderson EA, Gluckman E. Myelofibrosis with myeloid metaplasia. N Engl J Med 2000, 343:659-660.

8. Daly A, Song K, Nevill T et al. Stem cell transplantation for myelofibrosis: a report from two Canadian centers. Bone Marrow Transplant 2003,32: 35-40.

9. Ditschkowski M, Beelen DW, Trenschel R et al. Outcome of allogeneic stem cell transplantation in patients with myelofibrosis. Bone Marrow Transplant 2004, 34: 807-813. of patients. Since splenectomy is commonly performed in patients with larger splenomegaly, it can be hypothesized that splenectomy could be an indirect sign of a greater extension of the myeloproliferative disease before transplant, that could be associated to an higher risk of relapse after HSCT.

Conclusions: In conclusion, these results indicate that allogeneic SCT may be an attractive treatment approach for patients with high-risk MI. Although the outcome has been significantly improved in the last decade due to the reduction of TRM, several issues such as the timing of HSCT, the choice of the conditioning regimen, the source of stem cells, and the donor type have not been fully understood. Prospective studies that will explore new transplant modalities with the aims of reducing TRM and allow MI long-term control are warranted in this setting. The GITMO will promote a prospective study comparing two RIC regimes, fludarabinebusulfan versus fludarabine-thiotepa in patients with high-risk MI.

10. Rondelli D, Barosi G, Bacigalupo A, et al Allogeneic hematopoietic stem-cell transplantation with reducedintensity conditioning in intermediate- or high-risk patients with myelofibrosis with myeloid metaplasia. Blood 2005, 105: 4115-4119

11. Kroger N, Zabelina T, Schieder $\mathrm{H}$ et al. Pilot study of reduced-intensity conditioning followed by allogeneic stem cell transplantation from related and unrelated donors in patients with myelofibrosis. Br J Hematol 2005, 128: 690697.

12. Snyder DS, Palmer J, Stein AS et al. Allogeneic hematopoietic cell transplantation following reduced intensity conditioning for treatment of myelofibrosis. Biol Blood Marrow Transplant 2006, 12: 1161-1168.

13. Devine SM, Hoffman R, Verma A et al. Allogeneic blood cell transplantation following reduced-intensity conditioning is effective therapy for older patients with myelofibrosis with myeloid metaplasia. Blood 2002, 99: 2255-2258.

14. Merup M, Lazarevic V, Nahi H et al. Different outcome of allogeneic transplantation in myelofibrosis using conventional or reduced-intensity conditioning regimens. $\mathrm{Br}$ J Hematol 2006, 135: 367-373.

15. Patriarca F, Bacigalupo A, Sperotto A, et al., on benhalf of GITMO .Allogeneic hematopoietic stem cell transplantation in myelofibrosis: the twenty-year experience of GITMO (Gruppo Italiano Trapianto di Midollo Osseo). Hematologica 2008; 93: 1514-1522

16. Eder PE, Antman K, Elias A et al. Cyclophosphamide and thiotepa with autologous bone marrow transplantation in patients with solid tumors. J Natl Cancer Inst, 1988: 12211226.

17. Aversa F, Tabilio A, Terenzi A et al Successful engraftment of T-cell-depleted haploidentical 'three-loci' incompatible transplants in leukaemia patients by addition of recombinant human granulocyte colony-stimulating factor mobilized peripheral blood progenitor cells to bone marrow inoculum. Blood 1994, 84: 3948-3955. 
18. Rosales F, Naparstek E, Varadi G et al. The role of thiotepa in allogeneic stem cell transplantation in patients with leukaemia. Leuk Res 1999, 23: 947-952.

19. Bacigalupo A, Van Lint MT, Valbonesi M et al. Thiotepacyclophosphamide followed by granulocyte colonystimulating factor mobilized allogeneic peripheral blood cells in adults with advanced leukaemia. Blood 1998, 88: 353-357.

20. Raiola AM, Van Lint MT, Lamparelli T at al. Reducedintensity thiotepa-cyclophosphamide conditioning for allogeneic haemopoietic stem cell transplants (HSCT) in patients up to 60 years of age. Br J Hematol 2000, 109: 716721.

21. Corradini P, Dodero A, Farina L et al. Allogeneic stem cell transplantation following reduced-intensity conditioning can induce durable clinical and molecular remissions in relapsed lymphomas: pre-transplant disease status and histotype heavily influence outcome. Leukemia 2007, 21: 2316-2323.

22. Alessandrino EP, Della Porta GM, Bacigalupo A, et al.. WHO classification and WPSS predict posttransplantation outcome in patients with myelodisplastyc syndrome: a study from the Gruppo Italiano Trapianto di Midollo Osseo (GITMO) Blood 2008; 112: 895-902

23. Kroger N, Holler E, Kobbe G, et al. . Allogeneic stem cell transplantation after reduced intensity conditioning in patients with myelofibrosis: a multicenter prospective study of the Chronic Leukemia Working Party of the European
Group for Blood and Marrow Transplantation (EBMT) Blood 2009, 114: 5264-5270.

24. Kroger N, Badbaran A, Holler E et al. Monitoring of the JAK2-V617F mutation by highly sensitive quantitative realtime PCR after allogeneic stem cell transplantation in patients with myelofibrosis . Blood 2007, 109: 1316-1321

25. Kroger N, Thiele J, Zander A, et al. on behalf of of the Chronic Leukemia Working Party of the European Group for Blood and Marrow Transplantation (EBMT). Rapid regression of bone marrow fibrosis after dose-reduced allogeneic stem cell transplantation in patients with myelofibrosis. Experimental Hematology 2007; 35: 1719 1722.

26. Bacigalupo A. , Soraru M, Dominietto A, et al. Allogeneic hemopoietic SCT for patients with primary myelofibrosis: a predictive transplant score based on transfusion requirement, spleen size and donor type Bone Marrow Transplantation 2009, 1-6.

27. Li Z, Deeg HJ. Splenectomy and transplantation for myelofibrosis. Leukemia 2001; 15: 465-467.

28. Li Z, Gooley T, Applebaum FR, Deeg HJ. Splenectomy and hematopoietic stem cell transplantation in myelofibrosis. Blood 2001; 97:2180-2181

29. Mesa RA, Nagorney DS, Schwanger S et al. palliative goals, patient selection, and perioperative platelet management: outcome and lessons from 3 decades of splectomy for myelofibrosis with myeloid metaplasia at the Mayo Clinic. Cancer 2006; 107:361-370. 